\title{
England first, America second: The ecological predictors of life history and innovation- ERRATUM
}

\section{Erratum}

Cite this article: Luoto S, Rantala MJ, Krams I. (2019) England first, America second: The ecological predictors of life history and innovation-ERRATUM. Behavioral and Brain Sciences 42, e279: 1-4. doi:10.1017/ S0140525X19003248

\section{Severi Luoto $\bullet$, Markus J. Rantala and Indrikis Krams $\odot$}

Owing to project management and printer's errors, there were a number of mistakes in the original online version of the commentary by Luoto et al. (2019) on the target article by Baumard. The funding information was incorrect; there were errors in Table 2 of the commentary; and two references were omitted, resulting in further errors to in-text reference citations. The funding information and the errors in Table 2 have been corrected in the revised version of the treatment. The errors relating to references and their in-text citations are corrected to commentary reprinted below in this erratum.

We regret the errors.

Erratum References

Baumard N. (2019) Psychological origins of the Industrial Revolution. Behavioral and Brain Sciences 42:e189. doi:10.1017/S0140525X1800211X.

Luoto S., Rantala M. J. \& Krams I. (2019) England first, America second: The ecological predictors of life history and innovation. Behavioral and Brain Sciences 42:e205. doi:10.1017/ S0140525X19000165.

The complete commentary follows:

\section{England first, America second: The ecological predictors of life history and innovation}

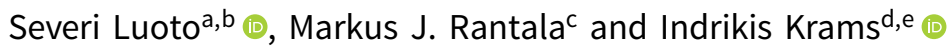

${ }^{a}$ English, Drama and Writing Studies, University of Auckland, 1010 Auckland, New Zealand; ${ }^{b}$ School of Psychology, University of Auckland, 1010 Auckland, New Zealand; 'Department of Biology, University of Turku, FIN-20014 Turku, Finland; ${ }^{\mathrm{d}}$ Department of Zoology and Animal Ecology, University of Latvia, 1004 Riga, Latvia and ${ }^{\mathrm{e}}$ Institute of Ecology and Earth Sciences, University of Tartu, 51014 Tartu, Estonia.

s.luoto@auckland.ac.nz_mjranta@utu.fi_indrikis.krams@ut.ee

https://www.researchgate.net/profile/Severi_Luoto https://www.researchgate.net/profile/Markus_Rantala https://www.researchgate.net/profile/Indrikis_Krams

doi:10.1017/S0140525X19000165, e205

\section{Abstract}

We present data from 122 nations showing that Baumard's argument on the ecological predictors of life history strategies and innovation is incomplete. Our analyses indicate that wealth, parasite stress, and cold climate impose orthogonal effects on life histories, innovation, and industrialization. Baumard also overlooks the historical exploitation of other nations which significantly enlarged the "pooled energy budget" available to England.

Baumard provides an intriguing application of Life History Theory by analyzing a major economic transition in world history. Despite the merits of his model, it is deficient in several important ways. Materials and sources used in our analyses are listed in Table 1. 
Table 1. (Luoto et al.) Materials and sources

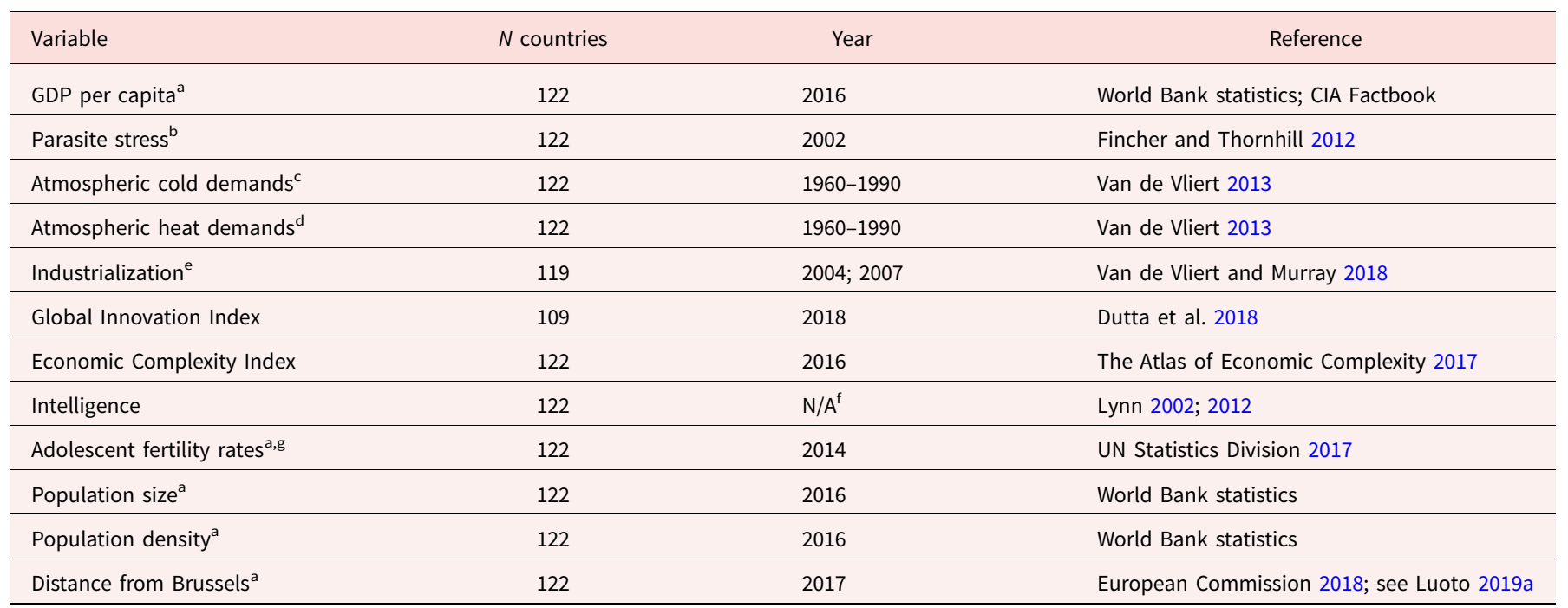

a Natural logarithm transformed because of high skew.

${ }^{b}$ Parasite stress data were collected from Fincher and Thornhill (2012), who used the World Health Organization (WHO) variable Infectious Disease DALY for the year 2002 to collate a variable called combined parasite stress.

${ }^{c}$ Atmospheric cold demands are coded as the sum of the absolute downward deviations from $22^{\circ} \mathrm{C}$ for the average lowest temperature in the coldest month, the average highest temperature in the coldest month, the average lowest temperature in the hottest month, and the average highest temperature in the hottest month (Van de Vliert 2013).

${ }^{\mathrm{d}}$ Atmospheric heat demands are the sum of the absolute upward deviations from $22^{\circ} \mathrm{C}$ for the average lowest temperature in the coldest month, the average highest temperature in the coldest month, the average lowest temperature in the hottest month, and the average highest temperature in the hottest month (Van de Vliert 2013).

e A factor score that represents the extent to which countries are engaged in industrial and service activities versus the agrarian sector (agriculture, fishing, and hunting)

${ }^{f}$ The relevant time frame of the data is unspecified in the source material.

$\mathrm{g}$ Births per 1,000 women aged 15-19.

\section{Pooled energy budget}

Baumard points out the increased wealth in England compared with rival nations, causally modelling this in Figure 2 through gradual technological accumulation. The "gilt elephant in the room" overlooked by Baumard is of course England's colonial history and slave trade (de Zwart \& van Zanden 2018). The concept of "pooled energy budget" (Kramer \& Ellison 2010; Krams et al. 2019) is useful for modelling English wealth and the nation's life history transition documented by Baumard. By exploiting the natural and human resources of other nations, by drawing energy from the resources and labour of other peoples, the English were able to substantially increase the pooled energy budget available to their own people. An important factor that sets England apart from other colonial powers is that its American colonies had a substantial production capacity and unprecedented population growth. Most material goods to fuel this growth were imported from England. This meant that England, which monopolized trade across the Atlantic, was able to pool a large amount of resources from its American colonies (de Zwart \& van Zanden 2018).

We argue that any life history model that seeks to explain the Industrial Revolution needs to account for this enlarged pool of energy that correspondingly disadvantaged other populations (such as native Americans and Africans, through genocide and slave trade). An increased energy budget can explain individualand population-level variation in central life history parameters, including marital and reproductive timing, investment in human capital formation, and immune function (de Pleijt 2018; Foreman-Peck \& Zhou 2018; Krams et al. 2019; Luoto 2019a). It is not sufficient to argue that "gradual technological accumulation" led to the higher pooled energy budget available for the English prior to the Industrial Revolution: it is also important to acknowledge the exploitation of other nations in that causal process.

\section{Different kinds of environmental harshness impose unique influences on innovation, life histories, and industrialization}

A further problem in Baumard's article is the myopic discussion of environmental harshness that overlooks the important selective role of climate on human behaviour. In short, Baumard argues that harsh environments favour fast life histories while in stable, predictable environments people can invest in the future, thus developing slower life histories. Baumard's model oversimplifies predictions that arise from life history accounts of human behaviour and innovation. It neglects the important influence that climate has on time orientation, life history strategies, innovative capacity, and economic development (Luoto 2019a; 2019b; Orosz et al. 2017).

Cold environments may impose selection pressures on organisms to invest in long-term orientation and cultural innovations (Luoto 2019a; 2019b, and references therein). Accordingly, the associations between atmospheric cold demands and various measures of innovation and industrialization are uniformly positive, strong, and significant (Table 2). Cold climate significantly predicts variation in innovation, economic complexity, and intelligence even when Gross Domestic Product (GDP) per capita, parasite stress, and heat demands are simultaneously entered into statistical models predicting innovation (Table 3). These effects remain significant when controlling for population size, population density, and distance from Central Europe (Table 4; see Luoto 2019a, for a rationale for using these controls). Importantly, cold climates may also select for slower life history strategies (Luoto 2019a; 2019b), as suggested by the 
Table 2. (Luoto et al.) Correlations among variables

\begin{tabular}{|c|c|c|c|c|c|c|c|c|c|c|c|c|}
\hline & Variable & 1 & 2 & 3 & 4 & 5 & 6 & 7 & 8 & 9 & 10 & 11 \\
\hline 1. & GDP per capita & & & & & & & & & & & \\
\hline 2. & Parasite stress & -.73 & & & & & & & & & & \\
\hline 3. & Cold demands & .44 & -.67 & & & & & & & & & \\
\hline 4. & Heat demands & -.32 & .38 & -.64 & & & & & & & & \\
\hline 5. & Industrialization & .81 & -.81 & .53 & -.35 & & & & & & & \\
\hline 6. & Global Innovation Index & .84 & -.69 & .56 & -.42 & .67 & & & & & & \\
\hline 7. & Economic complexity & .77 & -.70 & .58 & -.39 & .70 & .86 & & & & & \\
\hline 8. & Intelligence & .73 & -.76 & .66 & -.45 & .66 & .81 & .79 & & & & \\
\hline 9. & Adolescent fertility rate & -.74 & .77 & -.56 & .28 & -.70 & -.78 & -.75 & -.75 & & & \\
\hline 10. & Population size & -.15 & .34 & -.15 & .08 & -.25 & .01 & .04 & .01 & .11 & & \\
\hline 11. & Population density & .05 & -.13 & -.18 & .03 & .05 & .08 & .27 & .08 & -.15 & .24 & \\
\hline 12. & Distance from Brussels & -.45 & .60 & -.57 & .34 & -.49 & -.55 & -.56 & -.48 & .61 & .16 & -.21 \\
\hline
\end{tabular}

Table 3. (Luoto et al.) Multiple linear regression models without control variables ${ }^{\text {a }}$

\begin{tabular}{|c|c|c|c|c|c|}
\hline & Industrialization & Global innovation index 2018 & Economic complexity 2016 & Intelligence & Adolescent fertility $\left(\log _{e}\right)$ \\
\hline GDP & .474 & .755 & .582 & .397 & -.424 \\
\hline Parasite & -.450 & .039 & -.119 & -.267 & .375 \\
\hline Cold & .018 & .215 & .238 & .282 & -.203 \\
\hline Heat & -.021 & -.066 & -.007 & -.048 & -.125 \\
\hline$R^{2}$ & .77 & .75 & .67 & .70 & .68 \\
\hline VIF & $<3.23$ & $<3.47$ & $<3.25$ & $<3.25$ & $<3.25$ \\
\hline$n$ & 119 & 109 & 122 & 122 & 122 \\
\hline
\end{tabular}

${ }^{a}$ Standardized coefficients of four independent variables (GDP per capita, parasite stress, cold demands, heat demands) on five dependent variables (industrialization, innovation, economic complexity, intelligence, adolescent fertility). No control variables introduced in the model. For coefficients in boldface, $p<.01$.

Table 4. (Luoto et al.) Multiple linear regression models with three control variables ${ }^{\text {a }}$

\begin{tabular}{|c|c|c|c|c|c|}
\hline & Industrialization & Global innovation index 2018 & Economic complexity 2016 & Intelligence & Adolescent fertility $\left(\log _{e}\right)$ \\
\hline GDP & .472 & .725 & .596 & .354 & -.399 \\
\hline Parasite & -.461 & .030 & -.021 & -.422 & .338 \\
\hline Cold & .009 & .249 & .368 & .280 & -.159 \\
\hline Heat & -.024 & -.058 & .042 & -.051 & -.130 \\
\hline$R^{2}$ & .77 & .81 & .78 & .76 & .72 \\
\hline VIF & $<4.86$ & $<5.47$ & $<4.82$ & $<4.82$ & $<4.82$ \\
\hline$n$ & 119 & 109 & 122 & 122 & 122 \\
\hline
\end{tabular}

${ }^{a}$ Standardized coefficients of four independent variables (GDP per capita, parasite stress, cold demands, heat demands) on five dependent variables (industrialization, innovation, economic complexity, intelligence, adolescent fertility) when controlling for population size, population density, and distance from Central Europe. For coefficients in boldface, $p<.01$.

significant negative correlation between cold demands and adolescent fertility $(r=-.56$, Table 2$)$. These findings provide additional support for a theoretical framework that links cold climate with psychological dispositions and behaviours related to slow life history strategies and innovation (Luoto 2019a; 2019b).

It is noteworthy that heat demands impose less influence than cold demands on industrialization and innovation (Tables 2-4). 
Although cold climate significantly predicts increases in industrialization, innovation, and intelligence, heat demands and parasite stress are negatively associated with these variables (Table 2; see also Van de Vliert \& Murray 2018). These findings show that not all types of environmental harshness have similar effects on innovation and economic development. Cold demands impose selection pressures that are qualitatively different from those imposed by heat demands, parasite stress, and morbiditymortality (Barbaro \& Shackelford 2017; Van de Vliert \& Murray 2018). Baumard's generalization that all harshness has similar effects on life history strategies is inconsistent with existing theory and findings.

We point out these findings, not because we think they necessarily explain the specific life history transition that Baumard describes in England, but because Baumard's argument is inconsistent with what is known about the influence of climate on human psychological and behavioural dispositions. We agree with Baumard that the two mechanisms of natural selection and adaptive plasticity do not work at the same time scale, and that adaptive plasticity may be more suitable for explaining the specific instance of the Industrial Revolution. However, when viewed globally, and with recourse to deeper evolutionary time, adaptive plasticity explains innovation and economic development only partially (Luoto 2019a; 2019b). Any model on life history, time orientation, and innovation is incomplete without taking into consideration the cross-culturally robust influence of cold demands on human psychological dispositions and behavioural outcomes.

Whether climate can explain the psychological origins of the Industrial Revolution is a more specific question. We do not think this is the case. Although cold periods predict longitudinal variation in innovation with moderate accuracy, the Industrial Revolution was not preceded by particularly severe cold periods (Fig. 1B in De Dreu \& van Dijk 2018). Cold demands may be a more significant factor in predicting global patterns of innovation and economic development (Luoto 2019a; 2019b) rather than explaining the specific tide of events that led to the Industrial Revolution.

Despite its shortcomings, there is much to commend in Baumard's model. Understanding the various pre- and postnatal factors that affect the calibration of life history strategies (Luoto et al. 2019a; 2019b) and the importance of the "pooled energy budget" that was accomplished through English exploitation of other nations' natural and human resources will make Baumard's life history model biologically more compelling and historically more accurate.

Acknowledgments. This research was supported by the Emil Aaltonen Young Researcher Grant (S.L.), the Estonian Ministry of Education and Science (Grant PUT1223) (I.K.), and the Latvian Council of Science (Grant lzp-2018/1-0393) (I.K.).

\section{References}

[The letters " $a$ " and " $r$ " before author's initials stand for target article and response references, respectively]

Barbaro N. \& Shackelford T. K. (2017) Dimensions of environmental risk are unique theoretical constructs. Behavioral and Brain Sciences 40:12-13. [SL]

de Dreu C. K. \& van Dijk M. A. (2018) Climatic shocks associate with innovation in science and technology. PloS One 13(1):e0190122. [SL]

de Pleijt A. (2018) Human capital formation in the long run: Evidence from average years of schooling in England, 1300-1900. Cliometrica 12(1):99-126. Available at: https:// doi.org/10.1007/s11698-016-0156-3. [SL]

de Zwart P. \& van Zanden J. L. (2018) The origins of globalization: World trade in the making of the global economy, 1500-1800. Cambridge University Press. [SL]

Dutta S., Lanvin B. \& Wunsch-Vincent S., eds. (2018) The global innovation index 2018: Energizing the world with innovation, 11th edition. World Intellectual Property Organization. [SL]

European Commission (2018) Distance calculator. Available at: http://ec.europa.eu/dgs/ education_culture/tools/distance_en.htm. Retrieved January 1, 2018. [SL]

Fincher C. L. \& Thornhill R. (2012) Parasite-stress promotes in-group assortative sociality: The cases of strong family ties and heightened religiosity. Behavioral and Brain Sciences 35(2):61-79. [SL]

Foreman-Peck J. \& Zhou P. (2018) Late marriage as a contributor to the industrial revolution in England. The Economic History Review 71(4):1073-99. Available at: https:// doi.org/10.1111/ehr.12651. [SL]

Kramer K. L. \& Ellison P. T. (2010) Pooled energy budgets: Resituating human energy allocation trade-offs. Evolutionary Anthropology: Issues, News, and Reviews 19:136-47. [SL]

Krams I., Luoto S., Rubika A., Krama T., Elferts D., Kecko S., Skrinda I., Moore F., Krams R. \& Rantala M. J. (2019) A head start for life history development? Family income mediates associations between body height and immune response in men. American Journal of Physical Anthropology 168(3):421-27. [SL]

Luoto S. (2019a) An updated theoretical framework for human sexual selection: From ecology, genetics, and life history to extended phenotypes. Adaptive Human Behavior and Physiology 5(1):48-102. Available at: https://doi.org/10.1007/s40750-018-0103-6. [SL]

Luoto S. (2019b) Response to commentaries: Life history genetics, fluid intelligence, and extended phenotypes. Adaptive Human Behavior and Physiology. 5(1):112-15. https:// doi.org/10.1007/s40750-019-0109-8. [SL]

Luoto S., Krams I. \& Rantala M. J. (2019a) A life history approach to the female sexual orientation spectrum: Evolution, development, causal mechanisms, and health. Archives of Sexual Behavior 48(5):1273-308. Available at: https://doi.org/10.1007/s10508-0181261-0. [SL]

Luoto S., Krams I. \& Rantala M. J. (2019b) Response to commentaries: Life history evolution, causal mechanisms, and female sexual orientation. Archives of Sexual Behavior 48(5):1335-47. https://doi.org/10.1007/s10508-019-1439-0. [SL]

Lynn R. (2012) IQs predict differences in the technological development of nations from $1000 \mathrm{BC}$ through $2000 \mathrm{AD}$. Intelligence 40(5):439-44. [SL]

Lynn R. \& Vanhanen T. (2002) IQ and the wealth of nations. Praeger. [SL]

Orosz G., Zimbardo P. G., Boőthe B. \& Tóth-Király I. (2017) The paradoxical effect of climate on time perspective considering resource accumulation. Behavioral and Brain Sciences 40:e92. [SL]

The Atlas of Economic Complexity (2017) Country complexity rankings. Internet database. Available at: http://atlas.cid.harvard.edu/rankings/. Retrieved December 6, 2017. [SL]

UN Statistics Division (2017) World Development Indicators 2014. Internet database. Available at: http://data.un.org/Default.aspx. Retrieved December 20, 2017. [SL]

Van de Vliert E. (2013) White, gray, and black domains of cultural adaptations to climato-economic conditions. Behavioral and Brain Sciences 36(5):503-21. Available at: http://doi.org/10.1017/S0140525X13000277. [SL]

Van de Vliert E. \& Murray D. R. (2018) Climate and creativity: Cold and heat trigger invention and innovation in richer populations. Creativity Research Journal 30 (1):17-28. Available at: http://doi.org/10.1080/10400419.2018.1411571. [SL] 